\title{
Construct validity of the ProMIS laparoscopic simulator
}

\section{A. D. Gilliam}

Published online: 5 March 2009

(C) Springer Science+Business Media, LLC 2009

The report quite rightly highlighted reduced working time resulting in decreased operative exposure for trainees. This problem is worse in the United Kingdom than the United States due to the adoption of shift patterns rather than oncall pattern of work and a substantial increase in training posts, resulting in case dilution.

Another experience group the study could have included or a subset analysis that could have been performed involves consultant surgeons, who have performed more than 1,000 minimally invasive procedures, to determine whether they can outperform senior trainees or their peers in terms of dissection accuracy.

My recent visit to the Institute of Surgical and Interventional Simulation at the University of Washington Medical Center in Seattle leads me to believe that ease of surgical trainee access to simulators is key to encouragement of regular practicing and refining of skills.

\footnotetext{
A. D. Gilliam $(\square)$

Department of Surgery, James Cook University Hospital,

Middlesbrough, UK

e-mail: andrewgilliam@btinternet.com

A. D. Gilliam

Department of Surgery, North Tyneside Hospital,

Northshields, UK

Present Address:

A. D. Gilliam

Department of Surgery, Darlington Memorial Hospital,

Darlington, UK
}

Simulators need to be located conveniently in or around clinical areas, compact, and quick and easy to set up and dismantle. The Lap Sim system is one such system that provides immediate force (kinematic) and dynamic (position) feedback, unlike the ProMIS. It also sets the context of the procedure by a video before the assessment. A video library of operations reminding the trainee of the key steps also aids training by improving preparation before the procedure.

As virtual reality software improves, newer models of specific operations will be developed to allow more realistic interactive simulation. For example Lap Sim is able to provide some movement artifact, adding challenge to simulated tasks. 